\title{
Correlation between Gensini Score and Duration of Diabetes in Patients Undergoing Coronary Angiography
}

\author{
Razi Ul Amin ${ }^{1}$, Muhammad Anis M. Ahmedani ${ }^{1}$, Musa Karim ${ }^{2}$, Ahmed Raheem ${ }^{3}$ \\ 1. Cardiology, National Institute of Cardiovascular Diseases, Karachi, PAK 2. Miscellaneous, National Institute of \\ Cardiovascular Diseases, Karachi, PAK 3. Pathology, Aga Khan University Hospital, Karachi, PAK
}

Corresponding author: Musa Karim, mkarim.nicvd@gmail.com

\section{Abstract \\ Introduction}

The relationship between the duration of diabetes mellitus and coronary artery disease (CAD) is well established. Moreover, the Gensini score system is a reliable assessment tool for the severity of coronary artery disease (CAD). After an extensive literature search, we found that there is a knowledge gap about the relationship between the Gensini score and the duration of diabetes in our population. Therefore, the aim of this study was to find the relationship between the Gensini score and the duration of diabetes in patients undergoing a coronary angiography.

\section{Methods}

A cross-sectional study was conducted among 321 consecutively selected diabetic patients. Clinically diagnosed cases of diabetes on proper anti-diabetic treatment were included in this study. Patients with known severe $\mathrm{CAD}$ or history of coronary artery bypass grafting (CABG) surgery or primary coronary intervention (PCI) were excluded from the study. Coronary angiography was performed on all the patients and their Gensini score was calculated using the modified scoring schema. Duration of diabetes and other baseline risk factors were recorded for all patients. The relationship between the Gensini score and the duration of diabetes was assessed by calculating Pearson's correlation coefficient.

\section{Results}

A total of 321 diabetic patients were included in this study, out of which $67.9 \%$ (218) were men and mean \pm standard deviation age was $56.13 \pm 7.67$ years ranging between 40 to 70 years with a majority of the patients, $63.9 \%$ (205), being under 60 years of age. Along with diabetes, the most commonly observed risk factor was hypertension, which was observed in $77.6 \%$ (249) of the patients. Smoking and obesity were also observed in $18.7 \%$ (60) and $17.4 \%$ (56) of the patients, respectively. A significant positive correlation, 0.55 ( $\mathrm{p}<0.001$ ), was observed between the duration of diabetes and the Gensini scores. The correlation was found to be stronger

Received 01/22/2019 Review began 01/28/2019 Review ended 01/31/2019 Published 02/04/2019

๑) Copyright 2019 Ul Amin et al. This is an open access article distributed under the terms of the Creative Commons Attribution License CC-BY 3.0., which permits unrestricted use, distribution, and reproduction in any medium, provided the original author and source are credited. in older patients (more than 60 years of age) with a correlation coefficient of $0.52 \mathrm{vs} .0 .38$, and male patients with correlation coefficients of 0.66 vs. 0.34 .

\section{Conclusion}

A significant positive correlation between the Gensini score and the duration of diabetes mellitus was observed. This correlation is relatively stronger among male and older patients (more than 60 years of age).

Categories: Cardiology, Endocrinology/Diabetes/Metabolism

Keywords: diabetes, gensini score, duration, angiography, coronary artery disease

\section{Introduction}

Atherosclerosis in coronary arteries cause coronary artery disease (CAD), which is the cause behind most of the mortality as well as morbidity around the globe. Detection of atherosclerosis could be possible in its earlier subclinical asymptomatic stage, which gradually develops into the clinically overt disease with the passage of time [1-2]. Cardiovascular diseases have emerged as a major public health problem over the last couple of decades not only in developed countries but also in developing countries [3-4]. By 2020, annual deaths due to $\mathrm{CAD}$ is projected to rise to 11.1 million in developing countries, and mortalities due to coronary artery disease in 2020 are projected to rise by $137 \%$ among men and $120 \%$ among women as compared to 1990 in developing countries [5-6]. With the passage of time, diabetes mellitus (DM) is becoming an epidemic around the world; by 2030, the number of diabetic patients will probably rise to 366 million from 171 million in the year 2000 [7]. A large part of this increase is expected to derive from lowincome, underdeveloped, and developing countries such as South Asian countries, Sub-African countries, Latin America, and some parts of the Middle East [8]. 
In Pakistan, the number of people having DM is almost the same in both rural and urban areas, with $9.4 \%$ of the population in rural areas being affected by DM and 9.5\% in urban areas [9]. The World Health Organization (WHO) ranked Pakistan as the seventh most affected country by diabetes. However, these numbers may still be underreported, as there are many cases that go unreported or undiagnosed [9-10]. The high prevalence of diabetes, and the yearly increase in the number of reported cases, particularly of type two, in Pakistan poses not only a threat to the overall economy of the country, but also results in a poorer quality of life due to the high costs associated with care coupled with high rates of complications due to poor glycemic control [11].

Insulin resistance appears to be associated with $\mathrm{CAD}$ and hyperinsulinemia and is a positive free hazard for coronary heart disease (CHD). Additionally, insulin resistance adds to the advancement of cardiovascular risk factors [12]. It was proposed that the measurement of insulin resistance be added as a dependent of the severity of coronary artery disease (CAD) and more severe, multi-vessel, and long segment CAD was found in patients with diabetes lasting for more than five years as compared to those patients who had had diabetes for a duration of less than or equal to five years [13]. The Gensini score system is a technique developed by Gensini et al. [14], for the assessment of the severity of coronary artery disease (CAD). This scoring system is based on the artery morphology, coronary anatomy, and severity of stenosis in lesions [15]. A strong association of Gensini score was observed with long and short-term cardiovascular risk [16].

After an extensive literature search, only a few studies were found to have been published in our population that had studied the relationship between their Gensini score and the duration of diabetes. It is important to explore this relationship in our local population so that better management, counseling, and preventive strategies towards the risk reduction of CAD can be formulated for this subgroup of our population. Therefore, the aim of this study was to find the relationship between the Gensini score and the duration of diabetes in patients undergoing coronary angiography.

\section{Materials And Methods}

This study was carried out in the outpatient department of the National Institute of Cardiovascular Diseases (NICVD), after receiving approval from the ethics committee of NICVD (ERC-21/2018). The participants were fully informed about the study and written consent was obtained before their enrollment. Clinically diagnosed cases of diabetes on proper anti-diabetic treatment were included in this study. Patients with known severe $\mathrm{CAD}$ or prior history of coronary artery bypass grafting (CABG) surgery or primary coronary intervention (PCI) were excluded from the study. The coronary angiography was performed and interpreted by an interventional cardiologist who has more than five years of working experience. A modified Gensini score was calculated using the scoring schema defined by Gensini et al. [14]. In order to avoid observation bias, the Gensini scores were calculated by three independent cardiologists and a roundup of an average of the three was considered for the final analysis. The duration of diabetes was recorded in roundup years since the clinical confirmation of diabetes mellitus. Clinical characteristics such as hypertension (on antihypertensive medication for at least six months), obesity (calculated body mass index > $30 \mathrm{~kg} / \mathrm{m}^{2}$ ), and smoking (history of smoking in past one year) were obtained. All demographic and study variables were imported into SPSS Statistics for Windows, Version 21.0 (IBM Corp., Armonk, NY, US) and R software version 3.5.1 (The R Foundation for Statistical Computing). The Kolmogorov-Smirnov (KS) test was applied to the check the hypothesis of normality of distribution for both the study variables: duration of diabetes (years) and Gensini score. Mean \pm standard deviation (SD) was calculated and the two subgroups were compared by applying the Mann-Whitney U test. The relationship between the Gensini score and the duration of diabetes was assessed by calculating the Pearson's correlation. In addition, a significance criterion was set as p-value equals or below 0.05 .

\section{Results}

A total of 321 diabetic patients were included in this study, out of which $67.9 \%$ (218) were men and mean \pm standard deviation age was $56.13 \pm 7.67$ years ranging between 40 to 70 years with a majority of the patients, $63.9 \%$ (205), being under 60 years of age. Along with diabetes, the most commonly observed risk factor was hypertension, which was observed in $77.6 \%$ (249) patients. Smoking and obesity were observed in $18.7 \%(60)$ and $17.4 \%$ (56) patients, respectively. Mean body mass index (BMI) was calculated to be $26.53 \pm 4.38 \mathrm{~kg} / \mathrm{m}^{2}$. Baseline demographic characteristics are presented in Table 1. 


\section{Cureus}

Characteristics

Total $(n=321)$

Gender

Female

Male

Age

$\leq 60$ years

$>60$ years

Risk profile

Hypertension

Smoking

Obesity

Body mass index (BMI)

Duration of diabetes

Gensini score
103 [32.1\%]

218 [67.9\%]

$56.13 \pm 7.67$ years

205 [63.9\%]

116 [36.1\%]

249 [77.6\%]

60 [18.7\%]

$56[17.4 \%]$

$26.53 \pm 4.38 \mathrm{~kg} / \mathrm{m}^{2}$

$12.46 \pm 4.86$ years

$71.99 \pm 44.12$

TABLE 1: Baseline demographic characteristics

Diabetic duration was found to be $12.46 \pm 4.86$ years, ranging between 5 to 27 years. In addition, the mean Gensini score was calculated to be $71.99 \pm 44.12$, ranging between 4 and 226 . The hypothesis of normality of distribution for both the duration of diabetes and the Gensini score were rejected by Kolmogorov-Smirnov (KS) test $\mathrm{p}$-values of $<0.001$. A significant positive correlation, 0.55 ( $\mathrm{p}<0.001)$, was observed between the duration of diabetes and the Gensini scores. This relationship between the duration of diabetes and the Gensini scores has been presented in Figure 1.

Duration of diabetes vs. Gensini score

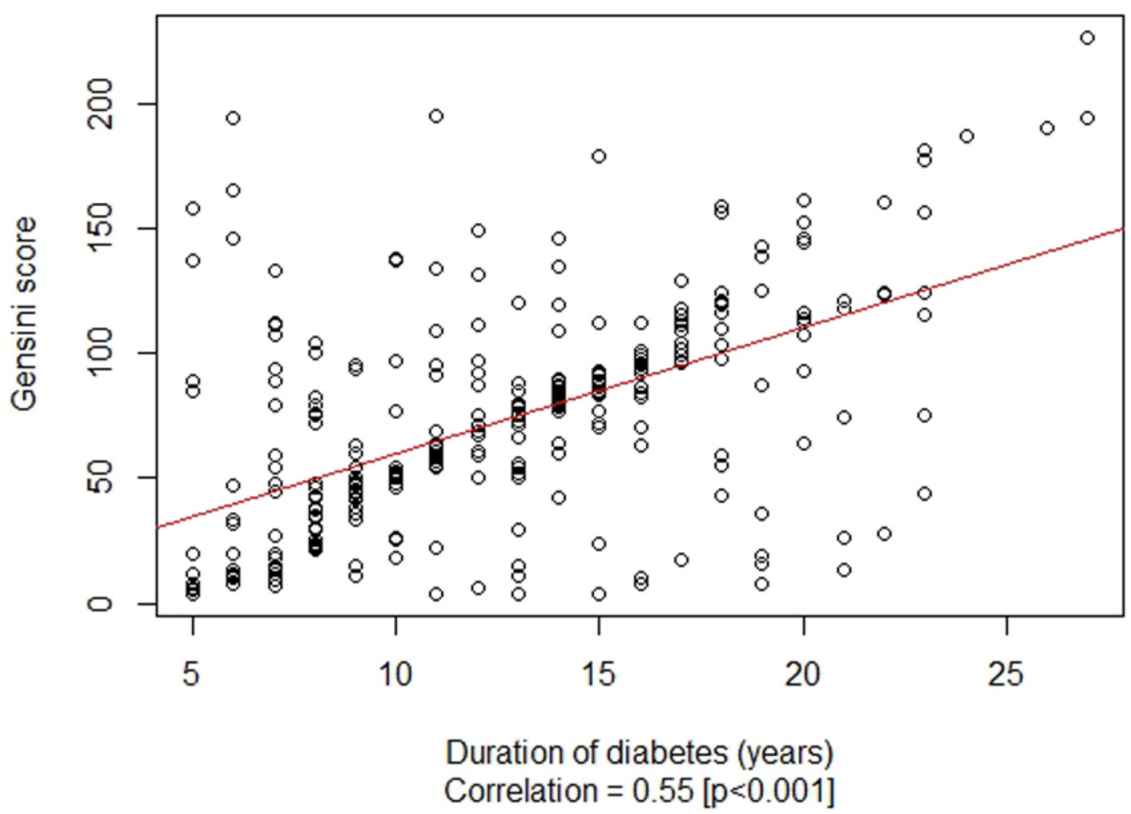

FIGURE 1: Correlation between the duration of diabetes mellitus (years) and Gensini score 
The differences in the duration of diabetes between the female and male subgroups was observed to be statistically insignificant at $12.25 \pm 4.95$ years vs. $12.56 \pm 4.82$ years, $p=0.547$ respectively. Similarly, the difference in the Gensini scores between the female and male subgroups was observed to be statistically insignificant at $73.31 \pm 45.71$ vs. $71.36 \pm 43.45, p=0.806$, respectively. Correlation between the duration of diabetes mellitus (years) and their Gensini score by gender are presented in Figure 2.

Male

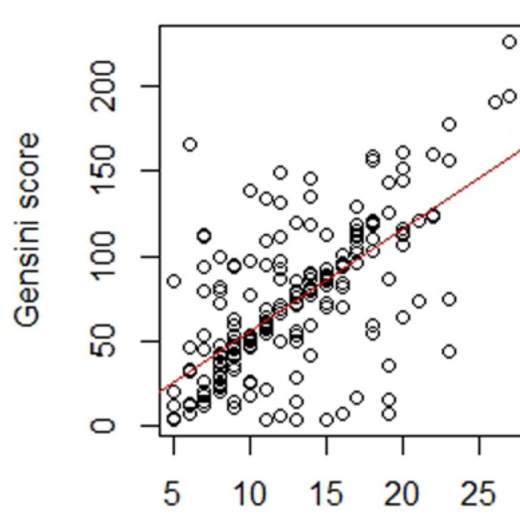

Duration of diabetes (years) Correlation $=0.66[p<0.001]$
Female

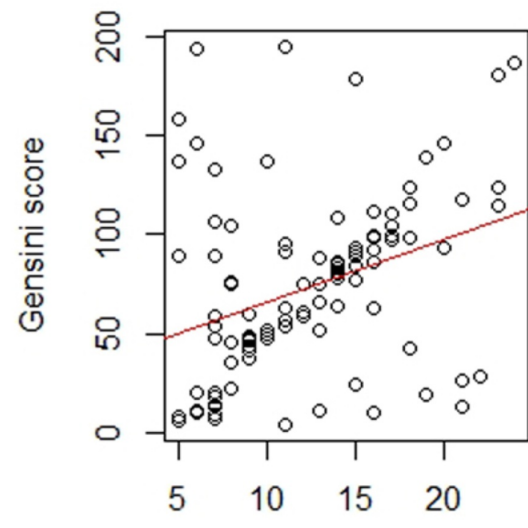

Duration of diabetes (years) Correlation $=0.34[p<0.001]$

FIGURE 2: Correlation between the duration of diabetes mellitus (years) and Gensini score by gender

The duration of diabetes and the Gensini scores were found to be much higher among the older age group (i.e., more than 60 years of age). The duration of diabetes was $10.74 \pm 3.84$ years vs. $15.51 \pm 4.99$ years, $\mathrm{p}<$ 0.001 for up to and more than 60 years of age, respectively. Similarly, the Gensini score was $58.36 \pm 36.92$ vs. $96.36 \pm 45.40, \mathrm{p}<0.001$ for up to and more than 60 years of age, respectively. The correlation between the duration of diabetes mellitus (years) and the Gensini score by age are presented in Figure 3.

Up to 60 years

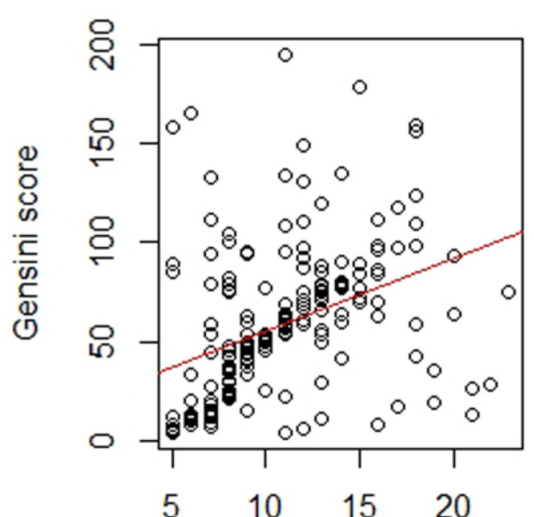

Duration of diabetes (years) Correlation $=0.38[p<0.001]$
More than 60 years

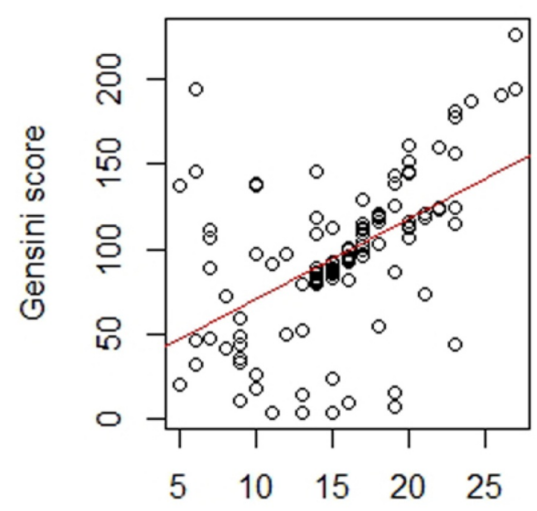

Duration of diabetes (years) Correlation $=0.52[p<0.001]$

FIGURE 3: Correlation between the duration of diabetes mellitus (years) and Gensini score by age 


\section{Cureus}

The difference in the duration of diabetes between the non-hypertensive and hypertensive subgroups was observed to be statistically insignificant at $12.32 \pm 5.57$ years vs. $12.50 \pm 4.60$ years, $p=0.429$, respectively. Similarly, the difference in the Gensini scores between the non-hypertensive and hypertensive subgroups was observed to be statistically insignificant at $72.96 \pm 51.75$ vs. $71.71 \pm 41.78, p=0.746$, respectively. The correlation between the duration of diabetes mellitus (years) and the Gensini score by hypertension status are presented in Figure 4.

Non-hypertensive

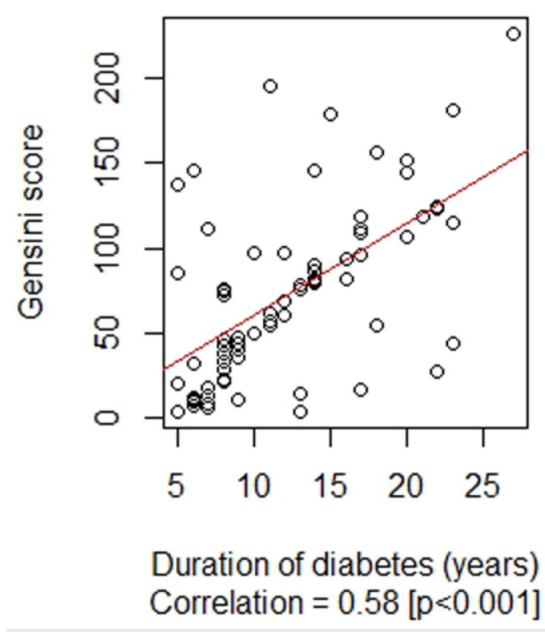

Hypertensive

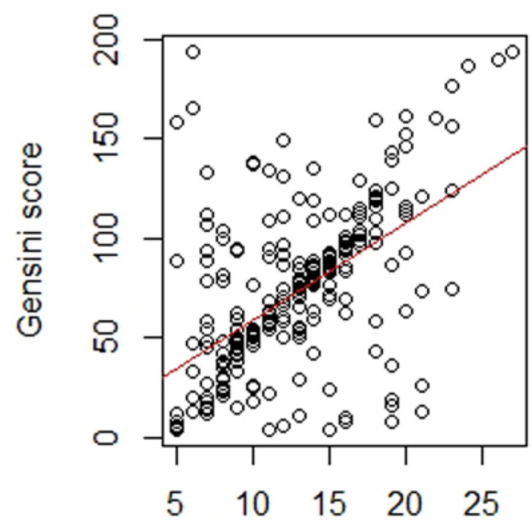

Duration of diabetes (years) Correlation $=0.54[p<0.001]$

FIGURE 4: Correlation between the duration of diabetes mellitus (years) and Gensini score by hypertension status

Similarly, baseline smoking status and obesity were found to have no statistically significant impact on the duration of diabetes and the Gensini score. The duration of diabetes mellitus (years) and the Gensini score by baseline smoking status and obesity are presented in Table 2 .

\begin{tabular}{|c|c|c|c|c|}
\hline Characteristics & Variable & Base (N) & Mean \pm SD & p-value \\
\hline \multirow{2}{*}{ Duration of diabetes (years) } & Non Smokers & 261 & $12.52 \pm 4.89$ & \multirow{2}{*}{0.699} \\
\hline & Smokers & 60 & $12.18 \pm 4.74$ & \\
\hline \multirow{2}{*}{ Ginisini Score } & Non Smokers & 261 & $73.32 \pm 44.67$ & \multirow{2}{*}{0.243} \\
\hline & Smokers & 60 & $66.18 \pm 41.51$ & \\
\hline \multirow{2}{*}{ Duration of diabetes (years) } & Non-Obese & 265 & $12.52 \pm 4.87$ & \multirow{2}{*}{0.699} \\
\hline & Obese & 56 & $12.2 \pm 4.84$ & \\
\hline \multirow{2}{*}{ Ginisini Score } & Non-Obese & 265 & $73.39 \pm 43.6$ & \multirow{2}{*}{0.176} \\
\hline & Obese & 56 & $65.36 \pm 46.34$ & \\
\hline
\end{tabular}

TABLE 2: Duration of diabetes mellitus (years) and Gensini score by baseline smoking status and obesity

p-values are based on the Mann-Whitney U test

\section{Discussion}

Diabetes mellitus (DM), especially type two, is firmly associated with the risk of cardiovascular disease (CVD) 
due to the multiple shared risk factors [17-18]. Epidemiologically, it is among the leading public health concerns of modern times, and it is attributed to an increased risk of cardiovascular morbidities and mortality [19]. Alongside its prognostic strength, diabetes is an important modifiable cardiovascular risk factor, and the duration of diabetes is associated with varying spectra of coronary artery disease [20]. Due to various lifestyle modifications and other causes, metabolic disorders are on the rise in developing countries such as Pakistan [21]. Therefore, in this study, we aim to assess the correlation between the duration of diabetes and the severity of coronary artery diseases as assessed by Gensini Score.

In our study group of 321 diabetic patients, the mean duration of diabetes was $12.46 \pm 4.86$ years, and the corresponding mean Gensini score was calculated to be $71.99 \pm 44.12$, with a significant positive correlation of $0.55(p<0.001)$ between the two variates. Both the duration of diabetes and the Gensini scores were statistically insignificant by gender; however, the strength of association between the two was relatively more strong among male patients compared to female patients, with correlation coefficients of 0.66 vs. 0.34 . Also, the duration of diabetes and Gensini score were found to be much higher among older patients (more than 60 years of age), and the association was found to be stronger in older patients (more than 60 years of age) with a correlation coefficient of 0.52 vs. 0.38 .

In our study, we found a positive correlation that is aligned with the findings of past studies [14,22-23]. In a study, two or three vessel disease was found to be more common (94.1\%) among patients with a diabetic duration of more than 10 years [24]. A study conducted in our local population by Salem et al. [23] reported a correlation coefficient of $0.36(\mathrm{p}=0.004)$ between the Gensini score and duration of diabetes. The correlation reported by Salem et al. [23] is relatively smaller than the correlation observed in our study. One potential reason for such discrepancy might be the effect of sample size differences between both studies.

One of the key limitations of this study is its cross-sectional nature along with single center coverage. Secondly, in this study, patients over 70 years of age were excluded from the study; therefore, the interaction of diabetes with CAD could not be found for the section of the population over 70 years of age. For the clinical utility of these findings, it needs to be further validated by multicenter large studies.

\section{Conclusions}

A significant positive correlation between the Gensini score and the duration of diabetes mellitus was observed. This correlation is relatively stronger among males and older patients (more than 60 years of age). Given this positive relationship, not only the presence of diabetes but also the duration of diabetes should be considered for the risk stratification of patients.

\section{Additional Information \\ Disclosures}

Human subjects: Consent was obtained by all participants in this study. National Institute of Cardiovascular Diseases (NICVD), Karachi issued approval ERC-21/2018. This study was conducted after the approval of the ethical review committee of the National Institute of Cardiovascular Diseases (NICVD), Karachi, Pakistan with the ethical approval number of ERC-21/2018. . Animal subjects: All authors have confirmed that this study did not involve animal subjects or tissue. Conflicts of interest: In compliance with the ICMJE uniform disclosure form, all authors declare the following: Payment/services info: All authors have declared that no financial support was received from any organization for the submitted work. Financial relationships: All authors have declared that they have no financial relationships at present or within the previous three years with any organizations that might have an interest in the submitted work. Other relationships: All authors have declared that there are no other relationships or activities that could appear to have influenced the submitted work.

\section{References}

1. Marini A, Naka KK, Vakalis K, et al.: Extent of coronary artery disease in patients undergoing angiography for stable or acute coronary syndromes. Hellenic J Cardiol. 2017, 58:115-121. 10.1016/j.hjc.2016.08.004

2. Weber C, Noels H: Atherosclerosis: current pathogenesis and therapeutic options. Nat Med. 2011, 17:14101422. $10.1038 / \mathrm{nm} .2538$

3. Salim MM, Nesa MF, Arif RM, Delwar HM, Masum MM: Association of glycosylated haemoglobin level with the severity of coronary artery disease in NSTEMI diabetic patients. Cardiovasc J. 2015, 8:43-48. 10.3329/cardio.v8i1.24767

4. Sakboonyarat B, Rangsin R: Prevalence and associated factors of ischemic heart disease (IHD) among patients with diabetes mellitus: a nation-wide, cross-sectional survey. BMC Cardiovasc Disord. 2018, 18:151. 10.1186/s12872-018-0887-0

5. Benjamin EJ, Blaha MJ, Chiuve SE, et al.: Heart disease and stroke statistics-2017 update: a report from the american heart association. Circulation. 2017, 135:e146-e603. 10.1161/CIR.0000000000000485

6. Okrainec K, Banerjee DK, Eisenberg MJ: Coronary artery disease in the developing world . Am Heart J. 2004, 148:7-15. 10.1016/j.ahj.2003.11.027

7. Shaw JE, Sicree RA, Zimmet PZ: Global estimates of the prevalence of diabetes for 2010 and 2030 . Diabetes Res Clin Pract. 2010, 87:4-14. 10.1016/j.diabres.2009.10.007

8. Wild S, Roglic G, Green A, Sicree R, King H: Global prevalence of diabetes: estimates for the year 2000 and 
projections for 2030. Diabet Care. 2004, 27:1047-1053. 10.2337/diacare.27.5.1047

9. Sheikh M: Diabetes mellitus-the continuing challenge. J Coll Physicians Surg Pak. 2004, 14:63-4.

10. Zhang X, Geiss LS, Cheng YJ, Beckles GL, Gregg EW, Kahn HS: The missed patient with diabetes: how access to health care affects the detection of diabetes. Diabetes Care. 2008, 31:1748-1753. 10.2337/dc08-0572

11. Basit A, Hydrie MZI, Hakeem R, Ahmedani MY, Masood Q: Frequency of chronic complications of type two diabetes. J Coll Physicians Surg Pak. 2004, 14:79-83.

12. Wang J, Luben R, Khaw K-T, Bingham S, Wareham NJ, Forouhi NG: Dietary energy density predicts the risk of incident type 2 diabetes the european prospective investigation of cancer (EPIC)-Norfolk study. Diabetes Care. 2008, 31:2120-2125. 10.2337/dc08-1085

13. Srinivasan MP, Kamath PK, Pai ND, Manjrekar PA, Mahabala C: Factors correlating with severity of coronary artery disease in type two diabetic patients on treatment for more than five years. Br J Med Med Res. 2014, 4:4364-4372. 10.9734/BJMMR/2014/11169

14. Gensini GG: A more meaningful scoring system for determining the severity of coronary heart disease . Am J Cardiol. 1983, 51:606. 10.1016/S0002-9149(83)80105-2

15. Sinning C, Lillpopp L, Appelbaum S, et al.: Angiographic score assessment improves cardiovascular risk prediction: the clinical value of SYNTAX and Gensini application. Clin Res Cardiol. 2013, 102:495-503. 10.1007/s00392-013-0555-4

16. Chen ZW, Chen YH, Qian JY, Ma JY, Ge JB: Validation of a novel clinical prediction score for severe coronary artery diseases before elective coronary angiography. PLoS One. 2014, 9:e94493. 10.1371/journal.pone.0094493

17. El-Adawy AH, Abdelaziz HM, Eid E, Gouda T: Association between albuminuria and severity of coronary artery disease detected by angiography in patients with type two diabetes mellitus. Int J Cardiovasc Res. 2017, 6:e1000335. 10.4172/2324-8602.1000335

18. Hu FB, Stampfer MJ, Haffner SM, Solomon CG, Willett WC, Manson JE: Elevated risk of cardiovascular disease prior to clinical diagnosis of type two diabetes. Diabetes Care. 2002, 25:1129-1134.

19. Bax JJ, Young LH, Frye RL, Bonow RO, Steinberg HO, Barrett EJ: Screening for coronary artery disease in patients with diabetes. Diabetes Care. 2007, 30:2729-2736. 10.2337/dc07-9927

20. Turnbull FM, Abraira C, Anderson RJ, et al.: Intensive glucose control and macrovascular outcomes in type 2 diabetes. Diabetologia. 2009, 52:2288-98. 10.1007/s00125-009-1470-0

21. Ramachandran A, Snehalatha C, Satyavani K, Vijay V: Impaired fasting glucose and impaired glucose tolerance in urban population in India. Diabet Med. 2003, 20:220-4. 10.1046/j.1464-5491.2003.00904.x

22. Parsa AF, Ghadirian L, Kanafi SR, Farsani EM: Positive correlation between microalbuminuria and severity of coronary artery stenosis in patients with type two diabetes mellitus. Acta Med Iran. 2013, 51:231-235.

23. Saleem T, Mohammad KH, Abdel-Fattah MM, Abbasi AH: Association of glycosylated haemoglobin level and diabetes mellitus duration with the severity of coronary artery disease. Diab Vasc Dis Res. 2008, 5:184189. $10.3132 /$ dvdr.2008.030

24. Kiuchi K, Nejima J, Takano T, Ohta M, Hashimoto H: Increased serum concentrations of advanced glycation end products: a marker of coronary artery disease activity in type two diabetic patients. Heart. 2001, 85:8791. 10.1136/heart.85.1.87 